\title{
Cell-surface nucleolin acts as a central mediator for carcinogenic, anti-carcinogenic, and disease-related ligands
}

\author{
Hirota Fujiki · Tatsuro Watanabe • Masami Suganuma
}

Received: 25 December 2013 / Accepted: 16 January 2014 / Published online: 28 January 2014

(C) The Author(s) 2014. This article is published with open access at Springerlink.com

\begin{abstract}
Purpose Cell-surface nucleolin in human gastric cancer cell lines is a receptor for TNF- $\alpha$-inducing protein (Tip $\alpha)$ of Helicobacter pylori. The binding complex of nucleolin and Tip $\alpha$ is internalized into the cells and then induces tumor progression of human gastric cancer. Surface nucleolin is also a receptor of human immunodeficiency virus-1, and the anti-HIV pseudopeptide (HB-19) showed anti-carcinogenic activity in vivo. Surface nucleolin has dual functions depending on the ligands: In order to understand the mechanisms of surface nucleolin, it is necessary to review surface nucleolin and its relation to carcinogenic ligands and anti-carcinogenic ligands. Other ligands can be grouped among disease-related ligands, which is an important new topic for the prevention of various ailments.

Results and discussion This paper mainly deals with two ligands of surface nucleolin, Tip $\alpha$ and pseudopeptide HB19. The binding complex of nucleolin and Tip $\alpha$ induces expression of $T N F-\alpha$ and chemokine genes and activates $\mathrm{NF}-\kappa \mathrm{B}$ in gastric cancer cells of humans and mice. However, when human gastric cancer cell line MKN-1 was transfected with nucleolin-targeted siRNA, the result was inhibition of cell migration and elongation induced by Tip $\alpha$. The amount of surface nucleolin was reduced in membrane fraction of the nucleolin knockdown MKN-1 cells, but the amount of nucleolin in the cytosol or nuclear fractions of the cells did not change. The results indicate that surface nucleolin acts as a carcinogenic mediator for Tip $\alpha$ of $H$. pylori. In contrast, both the viral external envelop glycoprotein gp120 of HIV and the anti-HIV pseudopeptide HB-19
\end{abstract}

H. Fujiki $(\square) \cdot$ T. Watanabe $\cdot$ M. Suganuma

Research Institute for Clinical Oncology, Saitama Cancer Center, Saitama 362-0806, Japan

e-mail: uv4h-fjk@asahi-net.or.jp bind to surface nucleolin. Through this binding, treatment with HB-19 inhibited tumor development in human breast cancer cell line MDA-MB-231 and rhabdoid tumor cell line derived from Wilms's tumor in xenograft nude mouse models. The results show that surface nucleolin acts as an anticarcinogenic mediator for HB-19.

Conclusion Based on these discrete functions of surface nucleolin, the binding complex of carcinogenic ligands and surface nucleolin seems to be competing with that of anticarcinogenic ligands and surface nucleolin. Moreover, carcinogenic ligands derived from endogenous sources play a significant role in human cancer development, and the interaction of surface nucleolin with disease-related ligands will be a new research subject for the prevention and treatment of various ailments.

Keywords Carcinogenic mediator $\cdot \mathrm{EMT} \cdot \mathrm{HB}-19$. Nucleolin $\cdot$ Tip $\alpha$

\section{Introduction}

Nucleolin, with a molecular weight of 105-110 kDa, initially called $\mathrm{C} 23$, is originally one of the 100 distinct proteins: It makes 5-10\% of total nucleolar protein in normal rat liver and Novikoff hepatoma ascites cells (Orrick et al. 1973; Bugler et al. 1982). Human nucleolin cDNA, containing the entire coding region, was isolated from lambda gt110 human retinal library, and the human nucleolin gene consists of 14 exons and 13 introns on chromosome 2q12qter (Srivastava et al. 1990). The translation of the nucleotide sequence predicted a 707-amino acid protein with several discrete domains (Srivastava et al. 1989), and amino acid sequence analysis of nucleolin revealed three structural domains: The N-terminal domain contains both highly 
acidic regions and multiple phosphorylation sites; the central domain contains four RNA-binding domains (RBD or $\mathrm{RRM}$ ); and the C-terminal domain (RGG or GAR) is rich in glycine, arginine, and phenylalanine residues (Ginisty et al. 1999). Nucleolin was previously thought to be a simple RNA-binding protein involved in the organization of nucleolar chromatin, packaging of pre-RNA, rDNA transcription, and ribosome assembly by shuttling between nucleus and cytoplasm; recent investigation has further revealed that nucleolin is involved in modulating transcriptional process, cytokinesis, nucleogenesis, signal transduction, apoptosis, induction of chromatin decondensation, and replication (Srivastava and Pollard 1999).

Although more than $90 \%$ of nucleolin is found in the nucleolus, phosphorylated nucleolin is found on the cell surface of logarithmically growing simian virus 40-transformed mouse fibroblasts (Pfeifle and Anderer 1983). Nucleolin has been classified into nuclear, cytoplasmic, and cell-surface nucleolins, depending on location in the cells; both nuclear and surface nucleolins are phosphorylated (Belenguer et al. 1989; Jordan et al. 1994). Nuclear nucleolin has $\mathrm{pI}$ values between $\mathrm{pH} 4.0$ and $\mathrm{pH}$ 6.0, and surface/cytoplasmic nucleolin is about $\mathrm{pH}$ 4.5. Cytoplasmic nucleolin is found in small vesicles that appear to translocate nucleolin to the cell surface, and this translocation is temperature dependent. Nucleolin is expressed at the cell surface, where it exists in close association with intracellular actin cytoskeleton, and surface nucleolin is clustered at the external side of plasma membrane (Hovanessian et al. 2000). The half-life of nuclear nucleolin is estimated to be more than $8 \mathrm{~h}$, while that of surface nucleolin is $<1 \mathrm{~h}$ (Hovanessian et al. 2010). Surface nucleolin is recently attracting great attention as an important receptor of cells for numerous ligands derived from various sources.

It is of interest to note that surface nucleolin plays a critical role in carcinogenesis, since endogenous ligands such as midkine, pleiotrophin, $\mathrm{P}$-selectin, and hepatocyte growth factor (HGF) are involved in carcinogenesis (Table 1) (Kadomatsu and Muramatsu 2004; Reyes-Reyes and Akiyama 2008; Tate et al. 2006). In our study on Helicobacter pylori (H. pylori) carcinogenesis, we discovered that tumor necrosis factor- $\alpha$ (TNF- $\alpha$ )-inducing protein (Tip $\alpha)$ of H. pylori is a carcinogenic factor that induces tumor promotion in vitro and in vivo (Suganuma et al. 2001, 2005). It was exciting for us to find that the exogenous ligand Tip $\alpha$ binds to surface nucleolin on human gastric cancer cell

Table 1 Ligands of surface nucleolin

\begin{tabular}{|c|c|c|c|}
\hline Ligands & Sources & Reported function & References \\
\hline \multicolumn{4}{|l|}{ Carcinogenic } \\
\hline Midkine & Endogenous & Mitogenic, transformation & Kadomatsu and Muramatsu (2004) \\
\hline Pleiotrophin & Endogenous & Mitogenic, transformation & Kadomatsu and Muramatsu (2004) \\
\hline Hepatocyte growth factor & Endogenous & Cancer development & Tate et al. (2006) \\
\hline K-Ras4B & Endogenous & Cancer development & Birchenall-Roberts et al. (2006) \\
\hline P-selectin & Endogenous & Signal transduction & Reyes-Reyes and Akiyama (2008) \\
\hline ErbB receptors & Endogenous & Malignant transformation & Di Segni et al. (2008) \\
\hline $\operatorname{Tip} \alpha$ & H. pylori & Tumor promotion and progression & Watanabe et al. (2010b) \\
\hline \multicolumn{4}{|l|}{ Anti-carcinogenic } \\
\hline HB-19 & Synthesized & Anti-HIV infection, anti-carcinogenic activity & Nisole et al. (2002) \\
\hline Lactoferrin & Cow's milk & Anti-carcinogenic activity & Legrand et al. (2004) \\
\hline AS1411/GROs & Synthesized & Anti-carcinogenic activity & Ireson and Kelland (2006) \\
\hline Endostatin & Endogenous & Anti-angiogenic, anti-carcinogenic activities & Shi et al. (2007) \\
\hline N6L & Synthesized & Anti-carcinogenic activity & Destouches et al. (2011) \\
\hline \multicolumn{4}{|l|}{ Disease-related } \\
\hline Lipoproteins & Endogenous & Lipid homeostasis & Semenkovich et al. (1990) \\
\hline Laminin & Endogenous & Neurite outgrowth & Kleinman et al. (1991) \\
\hline Fructosyllysine & Endogenous & Cell attachment & Krantz et al. (1995) \\
\hline Group B coxsackievirus & CVB & Viral infection & de Verdugo et al. (1995) \\
\hline Factor $\mathbf{J}$ & Endogenous & Complement inhibitor & Larrucea et al. (1998) \\
\hline HIV & HIV & Viral infection & Nisole et al. (1999) \\
\hline Elongation factor $\mathrm{Tu}$ & Francisella tularensis & Bacterial infection & Barel et al. (2008) \\
\hline Intimin- $\gamma$ & Escherichia coli $\mathrm{O} 157: \mathrm{H} 7$ & Bacterial adherence & Sinclair and O’Brien (2002) \\
\hline RSV & RSV & Viral infection & Tayyari et al. (2011) \\
\hline A $\beta 42$ & Endogenous & Alzheimer's disease & Ozawa et al. (2013) \\
\hline
\end{tabular}


lines and that internalization of the Tip $\alpha$ and nucleolin complex induces tumor progression and epithelial-mesenchymal transition (EMT) in human gastric cancer (Suganuma et al. 2008; Watanabe et al. 2013): Our study showed that the binding of Tip $\alpha$ to surface nucleolins is an essential step for $H$. pylori carcinogenesis in humans. Hovanessian and his colleagues discovered that surface nucleolin serves as a low-affinity receptor for human immunodeficiency virus-1 (HIV-1), and they further demonstrated that treatment with anti-HIV pseudopeptide HB-19 inhibits tumor development of human breast cancer and rhabdoid tumor cell lines in xenograft nude mouse models, mediated through surface nucleolin (Destouches et al. 2008; Krust et al. 2011b); HB19 treatment partly inhibits metastasis of melanoma cells to lymph nodes and lungs (El Khoury et al. 2010). In light of this evidence, it is necessary to look at the dual functions of surface nucleolin as a carcinogenic mediator and as an anti-carcinogenic mediator. This paper reviews the numerous functions of surface nucleolin and the relationship with carcinogenic and anti-carcinogenic ligands. Disease-related ligands that do not belong to the previous two types may show the way of preventing some ailments.

\section{Specificity of surface nucleolin}

The presence of surface nucleolin was first suggested by endogenously phosphorylated proteins on the surface of various cell lines and the phosphoprotein of simian virus 40-transformed mouse fibroblasts (Pfeifle et al. 1981; Pfeifle and Anderer 1983). Surface nucleolin was later identified in vitro in human hepatocellular carcinoma cell line HepG2, and in vivo in angiogenic endothelial cells within the vasculature (Semenkovich et al. 1990; Christian et al. 2003): It is a glycosylated protein found in various cells. Since extranuclear nucleolin undergoes $\mathrm{N}$ - and $\mathrm{O}$-glycosylations, it may be that glycosylation has a role in regulating the function of nucleolin (Carpentier et al. 2005). The $N$-linked glycosylation of cytoplasmic nucleolin is an essential step for the expression of surface nucleolin in various cells (Losfeld et al. 2009). Recently, Hovanessian and his colleagues found that surface nucleolin creates a 500$\mathrm{kDa}$ protein complex that consists of at least eight other proteins: two Wnt-related proteins A and B (WNT7A and WNT7B); Ku80 autoantigen; signal recognition particle (SRP) subunits 68 and 72; receptor for complement component $\mathrm{gClq}-\mathrm{R} / \mathrm{p} 32$, which lacks N-terminal 72 amino acids; and ribosomal proteins S4 and S6 (Krust et al. 2011a). The features of each protein can be briefly noted as follows: WNT7A and WNT7B are implicated in proliferation and differentiation of both normal and cancer cells (Kirikoshi and Katoh 2002); Ku80 antigen is present on the surface of leukemic and solid tumor cell lines, including $\mathrm{T}$ and
B lymphomas, myeloid leukemia, neuroblastoma, rhabdomyosarcoma, and breast carcinoma cells (Lynch et al. 2001); SRP68 and 72 are subunits of a ribonucleoprotein complex of 7S RNA and 6 proteins, and SRP is involved in major cellular machinery (Keenan et al. 2001); gClq$\mathrm{R}$, also known as hyaluronan-binding protein 1 (HABP 1), plays a significant role in bacterial infections, inflammation, and tumor progression (Bourguignon 2008; Rubinstein et al. 2004); S4 and S6 are components of 40S and $60 \mathrm{~S}$ ribosomal subunits, which build up ribosomal $80 \mathrm{~S}$, and many ribosomal protein genes act as cancer genes in zebra fish (Amsterdam et al. 2004). In addition, ligand binding to surface nucleolin induces high transitory $\mathrm{Ca}^{++}$membrane fluxes in the cells and elevates cell proliferation associated with expression of surface nucleolin levels (Losfeld et al. 2009). All the results show that proliferating cells have surface nucleolin on the plasma membrane and that surface nucleolin forms a large protein complex, but the interaction between the proteins and surface nucleolin has not been clearly established.

\section{Ligands of surface nucleolin}

Ligands are isolated from various sources. To make their functions clearer, they can be classified into three types, carcinogenic, anti-carcinogenic, and disease-related ligands (Table 1). Among carcinogenic ligands, midkine (MK) and pleiotrophin (PTN) are original heparin-binding growth factors, and $\mathrm{MK}$ is expressed in a wider rage of human carcinoma cells than PTN is (Kadomatsu and Muramatsu 2004); HGF regulates invasion and growth of carcinoma cells (Tate et al. 2006); K-Ras4B protein is a potent oncoprotein present in the nucleoli of both normal and transformed cells (Birchenall-Roberts et al. 2006); P-selectin binding to human colon carcinoma cell line Colo-320 forms a signaling complex with surface nucleolin (ReyesReyes and Akiyama 2008); ErbB receptor tyrosine kinases are major contributors to malignant transformation, and their interaction with nucleolin results in receptor dimerization and anchorage-independent growth (Di Segni et al. 2008); Tip $\alpha$ of $H$. pylori, a carcinogenic factor, will be described in more detail shortly (Watanabe et al. 2010b).

Among anti-carcinogenic ligands, HB-19 pseudopeptide is a potent inhibitor of HIV infection where it acts by blocking virus particle attachment (Nisole et al. 2002); lactoferrin (LF), found in mammalian secretions and blood, inhibits proliferation of cancerous mammary gland epithelial cells and also manifests a potent anti-viral activity against HIV and human cytomegalovirus (Legrand et al. 2004); AS1411, a 26-mer unmodified guanosine-rich oligonucleotide, induces growth inhibition of cancer cells in vitro and shows inhibition of human tumor xenografts in vivo (Ireson 
and Kelland 2006); guanosine-rich quadruplex-forming oligodeoxy nucleotides (GROs) are anti-carcinogenic ligands (Soundararajan et al. 2009); endostatin (ES), a 20-kDa $\mathrm{C}$-terminal globular domain of the collagen XVIII, was isolated from supernatant of a cultured murine hemangioendothelioma cell line, and it specifically inhibits proliferating endothelial cell growth and angiogenesis (Shi et al. 2007); N6L is a proapoptotic molecule and a synthetic ligand of surface nucleolin that inhibits the anchorage-dependent and anchorage-independent growth of cancer cell lines and angiogenesis (Destouches et al. 2011).

As for disease-related ligands, their functions are varied. Ligands that do not yet show carcinogenic or anticarcinogenic activities are grouped among the diseaserelated ligands, derived from various sources: Lipoproteins contained in apoB and apoE bind to surface nucleolin of HepG2 cells, which act as LDL receptors (Semenkovich et al. 1990); laminin is a potent promoter of neurite outgrowth (Kleinman et al. 1991); fructosyllysine is the main glucose adduct in the extracellular proteins formed by a condensation between $\varepsilon$-amino group of lysine and glucose by Amadori rearrangement and is found in human monocytes and monocyte-like cell line U937 (Krantz et al. 1995); group B coxsackieviruses (CVB) are enteroviruses of the family Picornaviridae and important human pathogens (de Verdugo et al. 1995); factor J (FJ), a soluble molecule found in urine and serum, is a complement inhibitor that regulates the pathways of a complement (Larrucea et al. 1998); HIV infects CD4 ${ }^{+}$target cells by fusion of the viral and cellular membranes through the external envelope glycoprotein gp120 (Nisole et al. 1999); elongation factor $\mathrm{Tu}$ (EF-Tu) of Francisella tularensis is a causative agent of tularemia that facilitates invasion of host tissue (Barel et al. $2008)$; intimin- $\gamma$ is an outer membrane protein of enterohemorrhagic Escherichia coli (EHEC) O157:H7 that colocalizes on the surface of HEp-2 cells with nucleolin (Sinclair and O'Brien 2002); human respiratory syncytial virus (RSV) causes an infectious disease worldwide, and it interacts with host-cell nucleolin through viral fusion envelope glycoprotein (Tayyari et al. 2011); amyloid- $\beta$ peptide 1-42 $(\mathrm{A} \beta 42)$ plays a key role in neurotoxicity of Alzheimer's disease, and it strongly binds to nucleolin, although $A \beta 40$ is weakly bound (Ozawa et al. 2013). In this paper, we will discuss various kinds of ligands and surface nucleolin in focusing on carcinogenic and anti-carcinogenic activities.

\section{TNF- $\alpha$ as an endogenous tumor promoter}

A tumor promoter induces clonal growth of initiated cells, resulting in tumor development. 12- $O$-tetradecanoylphorbol-13-acetate (TPA), teleocidin, and aplysiatoxin-the latter of which are structurally different from TPA—similarly induced potent tumor-promoting activity on mouse skin initiated with 7,12-dimethylbenz[a]anthracene (DMBA), mediated through activation of protein kinase C (Fujiki and Sugimura 1987). Moreover, okadaic acid and calyculin A, which are potent inhibitors of protein phosphatases 1 and $2 \mathrm{~A}$, are newly identified tumor promoters as potent as TPA on mouse skin initiated with DMBA (Fujiki and Suganuma 1993). In light of our evidence, we decided to look at endogenous tumor promoters in human carcinogenesis, focusing on the inflammatory cytokines. Our reasons are based on the "inflammation theory" of Rudolf Virchow from Berlin (Virchow 1858) and the carcinogenesis experiment on rabbit ear with coal tar of Katsusaburo Yamagiwa and Koichi Ichikawa in Tokyo (1915; Fujiki 2014). Their contributions led us to our current understanding that the relationship between inflammation and tumor development is strongly associated with up-regulation of NF-кB at the molecular level (Fujiki et al. 2013). We were fortunate to be able to demonstrate that the proinflammatory cytokine TNF- $\alpha$ induces transformation of BALB/3T3 cells initiated with 3-methylcholanthrene (MCA) (Komori et al. 1993), which showed that TNF- $\alpha$ is the essential cytokine in tumor promotion since okadaic acid did not show any tumorpromoting activities in TNF- $\alpha$-deficient $\left(\mathrm{TNF}-\alpha^{--}\right)$mice initiated with DMBA (Suganuma et al. 1999). Our further experiments revealed that TNF- $\alpha$ is strongly induced in organs of rodents by treatment with various tumor promoters, such as microcystin-LR and nodularin, and that the inflammatory cytokines and chemokines, such as TNF- $\alpha$, IL-1 and IL-6, are also thought to have tumor-promoting activities in human cancer development (Suganuma et al. 2002; Fujiki and Suganuma 2011). Based on all of these results, we found a tumor promoter gene in $H$. pylori genome that induces $T N F-\alpha$ gene expression.

\section{TNF- $\alpha$-inducing protein (Tip $\alpha)$ of $H$. pylori}

Helicobacter pylori membrane protein 1 (HP-MP1), one of the TNF- $\alpha$-inducing proteins, has a molecular weight of $16 \mathrm{kDa}$, and its structure is not related to any virulence factors of H. pylori (Yoshida et al. 1999). The transfection of $H P-M P 1$ gene into Bhas 42 cells, the putative initiated cells (v-Ha-ras-transfected BALB/3T3 cells), induced $T N F-\alpha$ gene expression with the levels ranging from 12.2to 27.0-fold higher than the basal levels of the parental Bhas 42 cells, and the transfected cells induced morphological changes in transformation (Suganuma et al. 2001). Because the Bhas 42 cells containing HP-MPl gene had shown strong tumorigenicity in nude mice (Fig. 1), we concluded that HP-MP1 protein induced $T N F-\alpha$ gene expression and TNF- $\alpha$ production in cooperation with v-Ha-ras gene product. To generalize the concept of TNF- $\alpha$-inducing 


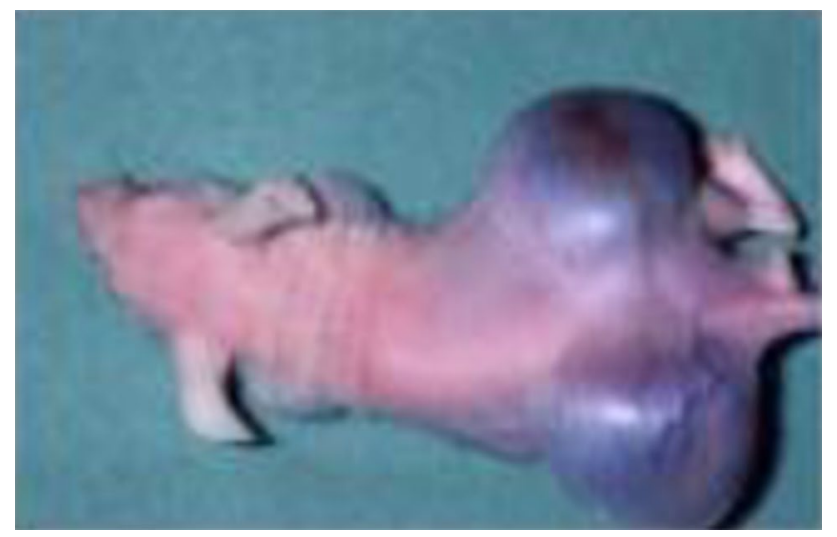

Fig. 1 Tumor development of Bhas 42 cells containing HP-MP1 gene in nude mice. Tumor-bearing mouse implanted with Bhas 42 cells containing $H P-M P 1$ gene 28 days later

protein as a tumor promoter, we discovered HP0596 gene, from $H$. pylori strain 26695, in silico from the complete genome sequence (Suganuma et al. 2005). HP0596 gene was $94.3 \%$ homologous to $H P-M P 1$ gene; the deduced amino acid sequence revealed that HP0596 protein has 172 amino acids with $19 \mathrm{kDa}$. We therefore designated HP0596 protein as the TNF- $\alpha$-inducing protein (Tip $\alpha$ ): The secreted amount of Tip $\alpha$ was determined using 28 clinical isolates of $H$. pylori obtained from 17 gastric cancer and 11 chronic gastritis patients. Clinical isolates from cancer patients secreted Tip $\alpha$ at 1.4-13.4 relative units, and those from gastritis patients secreted it at 0.8-6.7 relative units, suggesting that Tip $\alpha$ induces cancer development in human stomach infected with $H$. pylori. All tested strains of $H$. pylori secreted both $38-\mathrm{kDa}$ (dimer) and $19-\mathrm{kDa}$ (monomer) proteins in the medium, without dithiothreitol, in a manner independent of type IV secretion system of cagA (Suganuma et al. 2008). To study the molecular mechanisms, we made both recombinant $\operatorname{Tip} \alpha$ protein $(\operatorname{rTip} \alpha)$ and recombinant Tip $\alpha$ protein 6 amino acids deleted from N-terminal 2-7 (rdel-Tip $\alpha)$ as control, the latter of which lacks two cysteine residues, C5 and C7 (Suganuma et al. 2005).

The quaternary structure of rdel-Tip $\alpha$ showed that rdelTip $\alpha$ monomer A interacts with another monomer B, to form a heart-shaped dimer, and their circular dichroism spectra suggested that the structures of rdel-Tip $\alpha$ and Tip $\alpha$ homodimers are very similar (Tsuge et al. 2009). Encouraged by the above-mentioned results, we studied the specific binding protein for Tip $\alpha$ in mouse gastric cancer cell line MGT-40, using fluorescein isothiocyanate (FITC)labeled rTip $\alpha$. The specific binding of FITC-rTip $\alpha$ to MGT40 cells became saturated at a concentration of $5.0-7.5 \mu \mathrm{M}$, and this specific binding was inhibited by nonlabeled rTip $\alpha$ $\left(\mathrm{IC}_{50} 1.9 \mu \mathrm{M}\right)$, less weakly inhibited by rdel-rTip $\alpha\left(\mathrm{IC}_{50}\right.$
$20.0 \mu \mathrm{M})$. In addition, treatments of MGT-40 cells with FITC-rTip $\alpha$ at 37 or $4{ }^{\circ} \mathrm{C}$ showed that FITC-rTip $\alpha$ internalized into MGT-40 cells in a temperature-dependent manner (Suganuma et al. 2008). The results show that a dimer of rTip $\alpha$ with disulfide bonds binds to a receptor of Tip $\alpha$ on MGT-40 cells and that the receptor-binding complex with rTip $\alpha$ induces $T N F-\alpha$ and chemokine gene expressions in the nuclei of MGT-40 cells (Kuzuhara et al. 2007; Suganuma et al. 2012).

\section{Surface nucleolin as a receptor for Tip $\alpha$ of $H$. pylori}

To identify the specific rTip $\alpha$-binding protein, we made rTip $\alpha$-FLAG and rdel-Tip $\alpha$-FLAG, both of which carry a His-tag in the N-terminal and a FLAG-tag in the C-terminal regions: rTip $\alpha$-FLAG and rdel-Tip $\alpha$-FLAG perform the same biological activities as rTip $\alpha$ and rdel-Tip $\alpha$. After cell lysates of mouse gastric cancer cell line MGT-40 were incubated with rTip $\alpha$-FLAG or with rdel-Tip $\alpha$-FLAG in vitro at $4{ }^{\circ} \mathrm{C}$ for $2 \mathrm{~h}$, the polypeptides that coimmunoprecipitated with rTip $\alpha$-FLAG-but not rdel-Tip $\alpha$-FLAGwere further subjected to tryptic digestion and LC-MS analysis. Since $88-$ and $40-\mathrm{kDa}$ polypeptides that we obtained showed an identical peptide sequence to that of mouse nucleolin, their polypeptides were further subjected to immunoblot analysis with anti-nucleolin antibody. Pulldown assay using recombinant human nucleolin fragment showed that Tip $\alpha$ directly binds to nucleolin, and additional experiments with cell fractionation and flow cytometry confirmed that the $88-\mathrm{kDa}$ polypeptide is nucleolin, which is located on the cell surface of MGT-40: This was the first evidence that surface nucleolin acts as a Tip $\alpha$ receptor of H. pylori (Watanabe et al. 2010b). The results provide a new possibility to study gastric carcinogenesis of $H$. pylori using a nucleolin and Tip $\alpha$ complex.

\section{Role of surface nucleolin in gastric carcinogenesis in humans}

The cell lysates of five human gastric cancer cell lines were divided into membrane, cytosolic, and nuclear fractions, and each fraction was then subjected to SDS-PAGE and further immunoblotted with anti-nucleolin antibody. The amount of surface nucleolin was found to be large in MKN-45 (poorly differentiated adenocarcinoma), KATOIII (signet ring cell carcinoma), MKN-74 (moderately differentiated adenocarcinoma), and AGS (adenocarcinoma) cells; the amount was small in MKN-1 (adenosquamous carcinoma) cells, but all five cell lines contained similar amounts of nucleolin in the whole cell lysates (Watanabe et al. 2010a). In addition, the presence of surface nucleolin 
Fig. 2 Inhibition of nucleolin expression in MKN-1 cells transfected with nucleolintargeted siRNAs. a Nucleolin expression was determined in whole cell lysates. The cells were treated with nontransfection, siRNA-nc as control, and two nucleolin-targeted siRNAs, siRNA-n1 and siRNA-n2.

b Nucleolin expression was determined in membrane, cytosol and nuclear fractions in nontransfected and transfected cells, and nucleolin expression was compared with that of EGFR, HSP90, and lamin B proteins

\section{A Whole cell lysates}
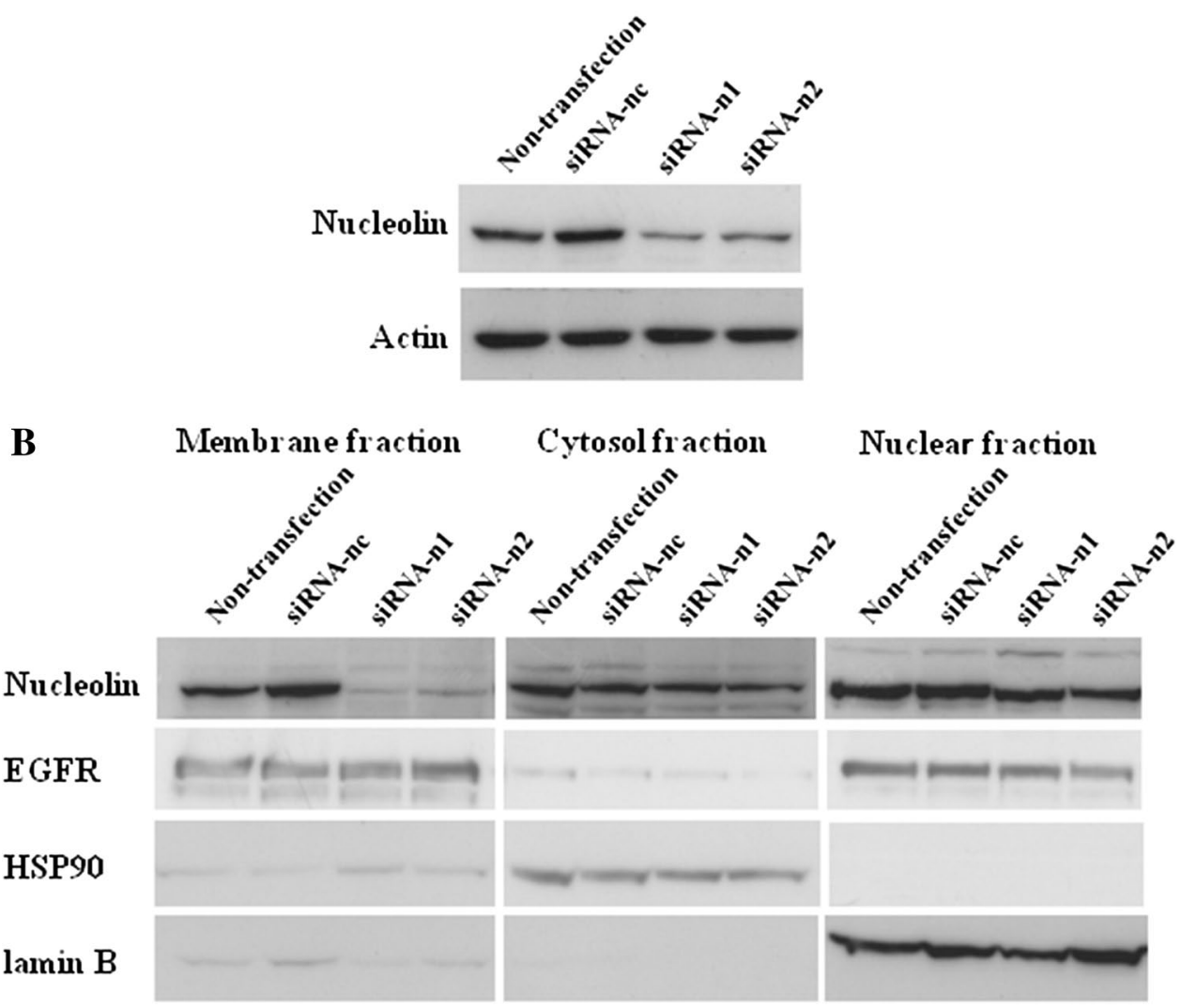

was confirmed in all the cell lines by flow cytometry after they were incubated with anti-nucleolin antibody (antiNUC295) or with preimmune serum in the presence of Alexa Fluor 488-conjugated goat anti-rabbit IgG. It is of interest to note that the amount of surface nucleolin in the normal epithelial membrane fraction of mouse glandular stomach is much lower than that in malignant MGT-40 cells, indicating that translocation of nucleolin to the cell surface occurs during carcinogenesis, making for easier binding to Tip $\alpha$ (Watanabe et al. 2010a). The results are well supported by previous evidence showing that the presence of surface nucleolin in various types of cells is closely associated with cell proliferation (Hovanessian et al. 2000).

The anti-carcinogenic aptamer AS1411, a DNA aptamer of 26-mer unmodified guanosine-rich nucleotide, binds to nucleolin and results in inhibition of nucleolin functions (Ireson and Kelland 2006; Soundararajan et al. 2009). We studied the inhibitory effects of AS1411 on cell growth of five human gastric cancer cell lines, and their $\mathrm{IC}_{50}$ values were in the range of 2.3 to $>20.0 \mu \mathrm{M}$, whereas control cytidine-rich oligonucleotide (CRO) of AS1411 did not show any inhibition. In addition, the incorporation of FITC-AS1411 into the cells of human gastric cancer cell line MKN-45 was detected within $2 \mathrm{~h}$, and the incorporated
FITC-AS1411 had colocalized with nucleolin in cytosol and nucleoli (Watanabe et al. 2010a).

To demonstrate the direct involvement of nucleolin in cell migration induced by rTip $\alpha$, the cells of human gastric cancer cell line MKN-1 were transfected with small interfering RNAs, nucleolin-targeted siRNA-n1 and siRNA-n2. The result was $50 \%$ reduction in the nucleolin in their cell lysates, whereas transfection with negative control siRNAnc did not reduce nucleolin (Fig. 2a). When cell lysates of the transfected cells were fractionated into membrane, cytosol, and nuclear fractions, transfection with siRNA-n1 and siRNA-n2 resulted in the reduction in nucleolin in the membrane fraction compared with that in the cytosol and nuclear fractions (Fig. 2b). Transfections with siRNA-n1 and siRNA-n2 into MKN-1 cells also inhibited cell migration induced by rTip $\alpha 60.4$ and $86.1 \%$, respectively, while inhibition with siRNA-nc as control was marginal (Fig. 3) (Watanabe et al. 2013). All the results showed that transfection with siRNA-n1 and siRNA-n2 significantly inhibited the effects of rTip $\alpha$, including cell migration, elongation, cell stiffness, and EMT, due to knockdown of surface nucleolin, which indicated that surface nucleolin is directly both a carcinogenic mediator for Tip $\alpha$ and an anti-carcinogenic mediator for AS1411. 


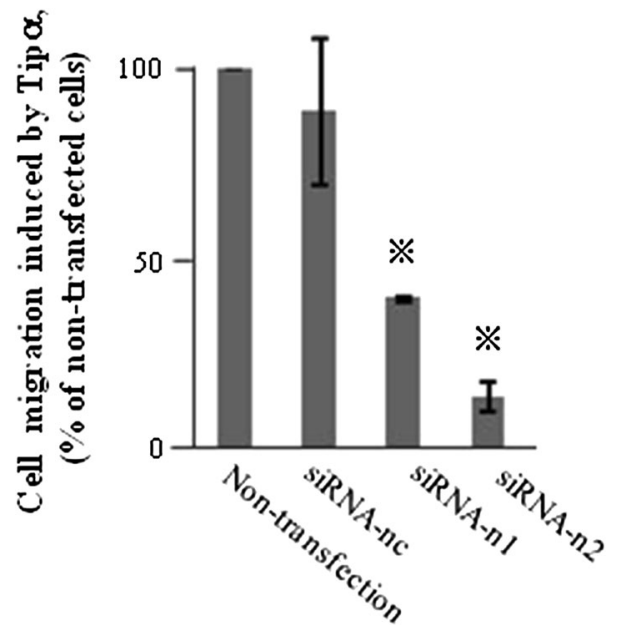

Fig. 3 Inhibition of Tip $\alpha$ induced cell migration in MKN-1 cells transfected with nucleolin-targeted siRNAs

\section{Surface nucleolin on $\mathrm{HeLa} \mathrm{CD4}^{+}$cells as a receptor of HIV-1 particle}

HIV is an envelope virus that infects target cells by the fusion of viral and cellular membranes. Hovanessian and his colleagues first found that the binding of HIV-1 particle to nucleolin on $\mathrm{HeLa} \mathrm{CD} 4^{+}$cells was inhibited by two substances: antibody against V3 loop domain of viral external envelope glycoprotein gp120 of HIV-1, which contains a hypervariable region of about 36 amino acids referred to as the V3 loop, and by V3 loop domain-mimicking pseudopeptide $5[\mathrm{~K} \psi(\mathrm{CH} 2 \mathrm{~N}) \mathrm{PR}]$-template-assembled synthetic peptide (TASP). The team also obtained the results showing that peudopeptide $5[\mathrm{~K} \psi(\mathrm{CH} 2 \mathrm{~N}) \mathrm{PR}]-\mathrm{TASP}$ (HB-19) inhibits $\mathrm{HIV}$ entry into $\mathrm{CD} 4^{+}$cells mediated through nucleolin (Callebaut et al. 1998).

Based on this evidence, their study was extended to examine inhibitory effects on cell growth and angiogenesis with HB-19, since surface nucleolin is implicated in growth of cancer cells and angiogenesis. When human breast cancer cell line MDA-MB-231 was injected into the mammary fat pad of female nude mice, palpable tumors approximately $40 \mathrm{~mm}^{3}$ in volume developed 2 weeks later, and the mice were randomly separated into three groups: The first group was given HB-19 (5 mg/kg) for 6 weeks; the second group was treated with tamoxifen $(10 \mathrm{mg} / \mathrm{kg})$ for 6 weeks; and the third group was given PBS only. Treatment with HB-19 reduced tumor weight $>95 \%$, and that with tamoxifen reduced it $80 \%$. In the next experiments, MDA-MB-231 cell line was inoculated into the flank of female athymic nude mice: Intraperitoneal administrations of HB-19 (i.p., $10 \mathrm{mg} / \mathrm{kg}$ ) three times per week for a period of 28 days resulted in more than $95 \%$ reduction in tumor volume throughout the experiment, and that

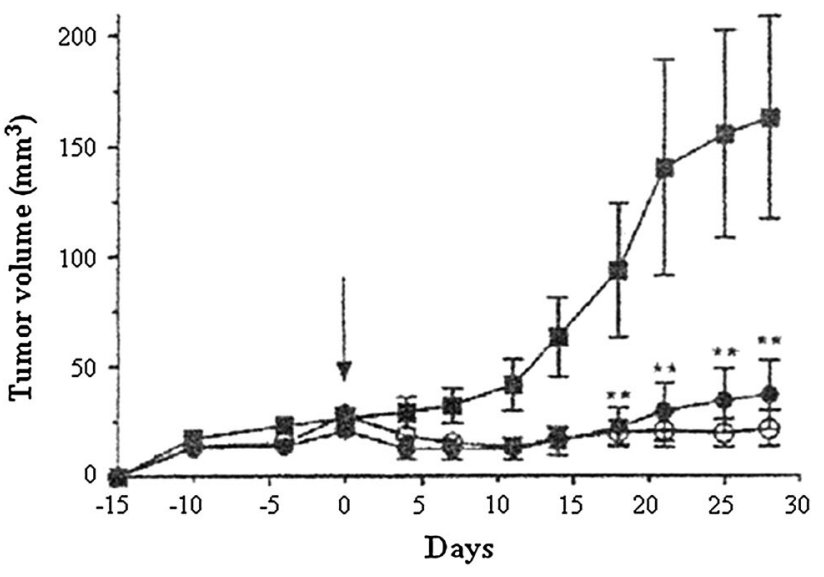

Fig. 4 Inhibition of tumor growth of human breast cancer cell line MDA-MB-231 in xenograft nude mouse model treated with PBS alone (filled square), HB-19 s.c. (filled circle), and HB-19 i.p. (open circle)

of subcutaneous administrations (s.c.) showed similarly strong reduction (Destouches et al. 2008) (Fig. 4). In this carcinogenesis experiment, it is not known which kinds of carcinogenic ligands were produced in MDA-MB-231 cells, but we assume that endogenous inflammatory cytokines and chemokines, which are able to bind to nucleolin, were probably involved in this tumor growth, since tumor promotion and progression are induced by inflammatory proteins (Fujiki et al. 2013). In addition, HB-19 treatment inhibited in vivo angiogenesis in chick embryo chorioallantoic membrane assay, so the results indicate that surface nucleolin itself is also a target for cancer treatment (Destouches et al. 2008).

Anti-carcinogenic activity of HB-19 was next examined using rhabdoid tumor cell line G401 derived from Wilms' tumor in nude mice. Nontreated G401 cells as control and G401 cells pretreated with HB-19 were separately inoculated into nude mice. The average tumor weight ( 5 mice) in control group was $2.36 \pm 1.25 \mathrm{~g}$ at day 50 of the experiment, whereas that of three mice in HB-19-treated group was $0.32 \pm 0.18 \mathrm{~g}$ (Krust et al. 2011b). The results show that HB-19 treatment inhibited the malignant growth of Wilms's tumor cells.

\section{Retardation of melanoma development in RET transgenic mice by HB-19}

$\mathrm{MT} / \mathrm{ret}^{+/-}$transgenic mice (RET mice) expressing the $r f p$ ret oncogene develop a spontaneous melanoma that constitutively enhances cRET protein expression in the development of melanoma in RET mice (Kato et al. 1998; Ohshima et al. 2010). To study the anti-carcinogenic activity of HB19, 10-day-old RET mice were treated with $50 \mu \mathrm{g}$ HB-19, 
Fig. 5 Inhibition of spontaneous melanoma development in RET mice by injections with HB-19. a Onset of first melanoma with HB-19 (dashed line) and nontreated control (dotted line), $p<0.001, \mathbf{b}$ onset of large melanoma $\left(>60 \mathrm{~mm}^{2}\right)$ with $\mathrm{HB}-$ 19 (dashed line) and nontreated control (dotted line), $p<0.001$
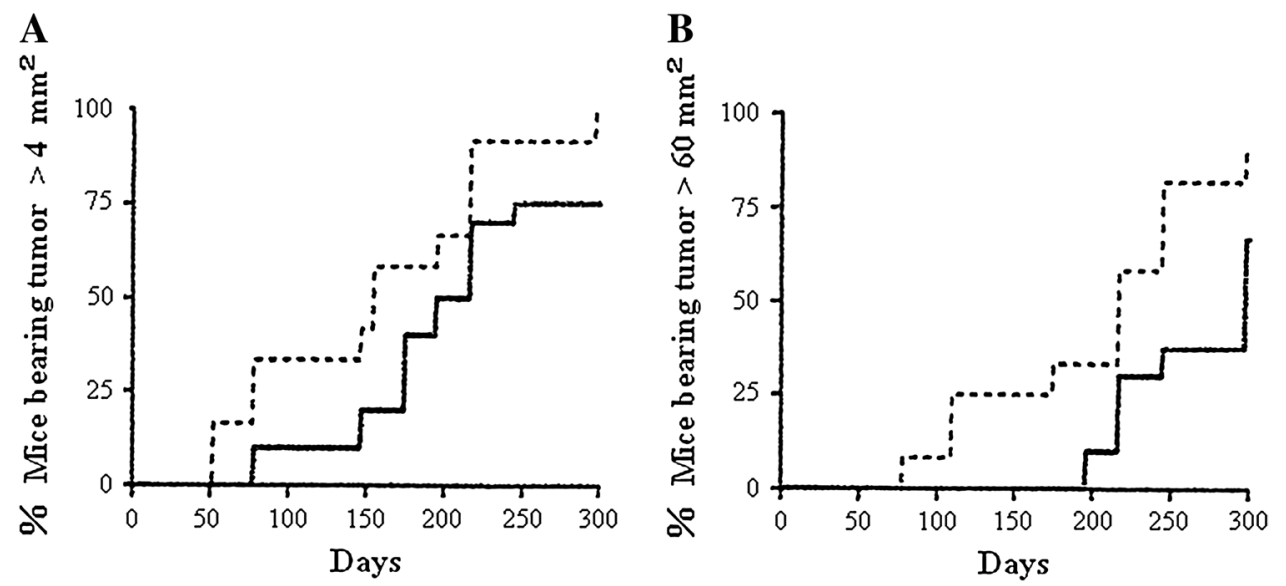

5 i.p. injections for the first week, $100 \mu \mathrm{g}$ for the second week, and $200 \mu \mathrm{g}$ for the rest of the experiment, and control mice received PBS only. The first melanoma in control group appeared at day 50 in the skin, while that in the HB19-treated group was found at day 75, suggesting that HB19 treatment delayed the onset of melanoma development (Fig. 5a). When the first appearance of a large melanoma (over $60 \mathrm{~mm}^{2}$ ) was next compared between the two groups, the difference was significant: Large melanoma of control group started to develop from day 75 , whereas that of the HB-19-treated group started from day 190, so HB-19 treatment delayed the development of melanoma, but did not eradicate it (Fig. 5b) (El Khoury et al. 2010). Melanoma cells have malignant features in which they metastasize to lymph nodes, mediastinum, and lungs. Eight of 11 control mice $(72.7 \%)$ showed either retroperitoneal metastasis or mediastinal adenopathies, whereas only three of nine mice $(33.3 \%)$ in the HB-19-treated group showed visceral or lung metastasis: HB-19 treatment partly prevented metastasis of melanoma cells in RET mice. Although the cRET protein is involved in the development of melanoma, it is not yet known whether it binds to surface nucleolin. In addition, the expression of $M M P-2, M M P-9$, and TNF$\alpha$ genes is significantly reduced in melanoma recovered from RET mice treated with HB-19: HB-19 seems to have potential for cancer treatment and prevention. The results strongly support the conclusion that surface nucleolin mediates the anti-carcinogenic activity of HB-19, since HB-19 binds to RGG domain at the C-terminal end of nucleolin (El Khoury et al. 2010).

\section{Discussion}

The function of surface nucleolin is now a hot topic in cancer research. Since numerous ligands are derived from various sources (Table 1), this paper discusses the interactions between surface nucleolin and Tip $\alpha$ of $H$. pylori as a model of human gastric carcinogenesis, and also the interaction between surface nucleolin and HB-19, an anti-HIV pseudopeptide, as a model of anti-carcinogenesis. The significance of tumor progression is the induction of EMT phenotypes in human cancer cells, i.e., cancer cells shut down the expression of numerous epithelial cell markers and induce the expression of mesenchymal proteins associated with metastatic states. Based on evidence showing that cells transfected with nucleolin-targeted small interfering RNAs resulted in inhibition of EMT phenotypes, including cell migration and elongation, experiments have clearly demonstrated that the EMT induced by Tip $\alpha$ is mediated through surface nucleolin (Watanabe et al. 2013).

The anti-carcinogenic activity of HB-19 is encouraging, as is that of aptamer AS1411. The binding affinity ( $K \alpha$ value) of HB-19 to V3-Bps containing nucleolin is $9.6 \times 10^{9} \mathrm{M}^{-1}, K \alpha$ value sufficient to inhibit HIV entry to the cells (Callebaut et al. 1998). The results strongly support evidence showing that HB-19 inhibits tumor development in xenograft nude mouse models, and we assume that the mechanisms of anti-carcinogenic activity are dependent on the competitive inhibition by HB-19 and AS1411 of various endogenous inflammatory carcinogenic ligands binding to nucleolin in vivo. Inhibitors of molecular interaction between surface nucleolin and its ligands have recently been reviewed looking at anti-carcinogenic activity (Koutsioumpa and Papadimitriou 2013).

It is remarkable that surface nucleolin binds to numerous ligands, such as DNA and RNA. An NMR study on the interaction of nucleolin with RNA revealed that the first two of four RNA-binding domains (RBDs) of nucleolin are responsible for the binding of nucleolin recognition element (NRE) of RNA molecule, because RBD1, RBD2, and the linker of nucleolin form a molecular clamp: NRE is sandwiched between RBD1 and RBD2 (Allain et al. 2000). If so, we can assume that the molecular clamp receives numerous ligands, including AS1411 (Arumugam et al. 2010). 
It is difficult to show precisely how the dual functions of surface nucleolin are determined by ligands, or what the interaction of surface nucleolin with each protein of a nucleolin protein complex is; what we think is that the binding site of surface nucleolin is constantly occupied by endogenous ligands in vivo and that this leads to carcinogenic development in humans. Moreover, the disease-related ligands need to be further investigated, because of significant ailments.

Since studies on the conditional nucleolin knockout cells and inactivation of nucleolin with siRNA in HeLa cells have indicated that nucleolin is absolutely required for proliferation and survival of these cells (Storck et al. 2009; Ugrinova et al. 2007), it is not physiologically possible to completely block the function of surface nucleolin in the cells and in vivo. In order to use surface nucleolin as a therapeutic tool, the chemical and biochemical features of ligands and characterizations of surface nucleolin in target cells need to be further investigated. In summary, surface nucleolin is a carcinogenic, anti-carcinogenic, and diseaserelated mediator, certainly worth intensive further study.

Acknowledgments We thank Drs. Kazuya Hirano, Masatoshi Beppu, Hideaki Tsuge, Kensei Yamaguchi, Atsushi Takahasi, Anupom Mondal, Zhenghao Li, and Yoichi Tanaka for their stimulating collaboration. This work was supported by the Smoking Research Foundation and Urakami Foundation.

Conflict of interest Here, we declare that we have no conflict of interest.

Open Access This article is distributed under the terms of the Creative Commons Attribution License which permits any use, distribution, and reproduction in any medium, provided the original author(s) and the source are credited.

\section{References}

Allain FH, Bouvet P, Dieckmann T, Feigon J (2000) Molecular basis of sequence-specific recognition of pre-ribosomal RNA by nucleolin. EMBO J 19(24):6870-6881

Amsterdam A, Sadler KC, Lai K, Farrington S, Bronson RT, Lees JA, Hopkins N (2004) Many ribosomal protein genes are cancer genes in zebrafish. PLoS Biol 2(5):E139

Arumugam S, Miller MC, Maliekal J, Bates PJ, Trent JO, Lane AN (2010) Solution structure of the RBD1,2 domains from human nucleolin. J Biomol NMR 47(1):79-83

Barel M, Hovanessian AG, Meibom K, Briand JP, Dupuis M, Charbit A (2008) A novel receptor-ligand pathway for entry of Francisella tularensis in monocyte-like THP-1 cells: interaction between surface nucleolin and bacterial elongation factor Tu. BMC Microbiol 8:145

Belenguer P, Baldin V, Mathieu C, Prats H, Bensaid M, Bouche G, Amalric F (1989) Protein kinase NII and the regulation of rDNA transcription in mammalian cells. Nucleic Acids Res 17(16):6625-6636

Birchenall-Roberts MC, Fu T, Kim SG, Huang YK, Dambach M, Resau JH, Ruscetti FW (2006) K-Ras4B proteins are expressed in the nucleolus: interaction with nucleolin. Biochem Biophys Res Commun 348(2):540-549
Bourguignon LY (2008) Hyaluronan-mediated CD44 activation of RhoGTPase signaling and cytoskeleton function promotes tumor progression. Semin Cancer Biol 18(4):251-259

Bugler B, Caizergues-Ferrer M, Bouche G, Bourbon H, Amalric F (1982) Detection and localization of a class of proteins immunologically related to a $100-\mathrm{kDa}$ nucleolar protein. Eur J Biochem 128(2-3):475-480

Callebaut C, Blanco J, Benkirane N, Krust B, Jacotot E, Guichard G, Seddiki N, Svab J, Dam E, Muller S, Briand JP, Hovanessian AG (1998) Identification of V3 loop-binding proteins as potential receptors implicated in the binding of HIV particles to CD4(+) cells. J Biol Chem 273(34):21988-21997

Carpentier M, Morelle W, Coddeville B, Pons A, Masson M, Mazurier J, Legrand D (2005) Nucleolin undergoes partial $N$ - and $O$-glycosylations in the extranuclear cell compartment. Biochemistry (Mosc) 44(15):5804-5815

Christian S, Pilch J, Akerman ME, Porkka K, Laakkonen P, Ruoslahti E (2003) Nucleolin expressed at the cell surface is a marker of endothelial cells in angiogenic blood vessels. J Cell Biol 163(4):871-878

de Verdugo UR, Selinka HC, Huber M, Kramer B, Kellermann J, Hofschneider PH, Kandolf R (1995) Characterization of a 100-kilodalton binding protein for the six serotypes of coxsackie B viruses. J Virol 69(11):6751-6757

Destouches D, El Khoury D, Hamma-Kourbali Y, Krust B, Albanese P, Katsoris P, Guichard G, Briand JP, Courty J, Hovanessian AG (2008) Suppression of tumor growth and angiogenesis by a specific antagonist of the cell-surface expressed nucleolin. PLoS One 3(6):e2518

Destouches D, Page N, Hamma-Kourbali Y, Machi V, Chaloin O, Frechault S, Birmpas C, Katsoris P, Beyrath J, Albanese P, Maurer M, Carpentier G, Strub JM, Van Dorsselaer A, Muller S, Bagnard D, Briand JP, Courty J (2011) A simple approach to cancer therapy afforded by multivalent pseudopeptides that target cellsurface nucleoproteins. Cancer Res 71(9):3296-3305

Di Segni A, Farin K, Pinkas-Kramarski R (2008) Identification of nucleolin as new ErbB receptors-interacting protein. PLoS One 3(6): 2310

El Khoury D, Destouches D, Lengagne R, Krust B, Hamma-Kourbali Y, Garcette M, Niro S, Kato M, Briand JP, Courty J, Hovanessian AG, Prévost-Blondel A (2010) Targeting surface nucleolin with a multivalent pseudopeptide delays development of spontaneous melanoma in RET transgenic mice. BMC Cancer 10:325

Fujiki H (2014) Gist of Dr. Katsusaburo Yamagiwa's papers entitled "Experimental study on the pathogenesis of epithelial tumors" (I to VI reports). Cancer Sci. doi:10.1111/cas.12333

Fujiki H, Suganuma M (1993) Tumor promotion by inhibitors of protein phosphatases 1 and 2A: the okadaic acid class of compounds. Adv Cancer Res 61:143-194

Fujiki H, Suganuma M (2011) Tumor promoters-microcystin-LR, nodularin and TNF- $\alpha$ and human cancer development. Anticancer Agents Med Chem 11(1):4-18

Fujiki H, Sugimura T (1987) New classes of tumor promoters: teleocidin, aplysiatoxin, and palytoxin. Adv Cancer Res 49:223-264

Fujiki H, Sueoka E, Suganuma M (2013) Tumor promoters: from chemicals to inflammatory proteins. J Cancer Res Clin Oncol 139(10):1603-1614

Ginisty H, Sicard H, Roger B, Bouvet P (1999) Structure and functions of nucleolin. J Cell Sci 112(Pt 6):761-772

Hovanessian AG, Puvion-Dutilleul F, Nisole S, Svab J, Perret E, Deng JS, Krust B (2000) The cell-surface-expressed nucleolin is associated with the actin cytoskeleton. Exp Cell Res 261(2):312-328

Hovanessian AG, Soundaramourty C, El Khoury D, Nondier I, Svab J, Krust B (2010) Surface expressed nucleolin is constantly induced in tumor cells to mediate calcium-dependent ligand internalization. PLoS One 5(12):e15787 
Ireson CR, Kelland LR (2006) Discovery and development of anticancer aptamers. Mol Cancer Ther 5(12):2957-2962

Jordan P, Heid H, Kinzel V, Kubler D (1994) Major cell surface-located protein substrates of an ecto-protein kinase are homologs of known nuclear proteins. Biochemistry (Mosc) 33(49):14696-14706

Kadomatsu K, Muramatsu T (2004) Midkine and pleiotrophin in neural development and cancer. Cancer Lett 204(2):127-143

Kato M, Takahashi M, Akhand AA, Liu W, Dai Y, Shimizu S, Iwamoto T, Suzuki H, Nakashima I (1998) Transgenic mouse model for skin malignant melanoma. Oncogene 17(14):1885-1888

Keenan RJ, Freymann DM, Stroud RM, Walter P (2001) The signal recognition particle. Annu Rev Biochem 70:755-775

Kirikoshi H, Katoh M (2002) Expression of WNT7A in human normal tissues and cancer, and regulation of WNT7A and WNT7B in human cancer. Int J Oncol 21(4):895-900

Kleinman HK, Weeks BS, Cannon FB, Sweeney TM, Sephel GC, Clement B, Zain M, Olson MO, Jucker M, Burrous BA (1991) Identification of a 110-kDa nonintegrin cell surface laminin-binding protein which recognizes an A chain neurite-promoting peptide. Arch Biochem Biophys 290(2):320-325

Komori A, Yatsunami J, Suganuma M, Okabe S, Abe S, Sakai A, Sasaki K, Fujiki H (1993) Tumor necrosis factor acts as a tumor promoter in BALB/3T3 cell transformation. Cancer Res 53(9):1982-1985

Koutsioumpa M, Papadimitriou E (2013) Cell surface nucleolin as a target for anti-cancer therapies. Recent Pat Anticancer Drug Discov [Epub ahead of print]

Krantz S, Salazar R, Brandt R, Kellermann J, Lottspeich F (1995) Purification and partial amino acid sequencing of a fructosyllysine-specific binding protein from cell membranes of the monocyte-like cell line U937. Biochim Biophys Acta 1266(1):109-112

Krust B, El Khoury D, Nondier I, Soundaramourty C, Hovanessian AG (2011a) Targeting surface nucleolin with multivalent HB-19 and related Nucant pseudopeptides results in distinct inhibitory mechanisms depending on the malignant tumor cell type. BMC Cancer 11:333

Krust B, El Khoury D, Soundaramourty C, Nondier I, Hovanessian AG (2011b) Suppression of tumorigenicity of rhabdoid tumor derived G401 cells by the multivalent HB-19 pseudopeptide that targets surface nucleolin. Biochimie 93(3):426-433

Kuzuhara T, Suganuma M, Kurusu M, Fujiki H (2007) Helicobacter pylori-secreting protein Tip $\alpha$ is a potent inducer of chemokine gene expressions in stomach cancer cells. J Cancer Res Clin Oncol 133(5):287-296

Larrucea S, González-Rubio C, Cambronero R, Ballou B, Bonay P, López-Granados E, Bouvet P, Fontán G, Fresno M, López-Trascasa M (1998) Cellular adhesion mediated by factor J, a complement inhibitor. Evidence for nucleolin involvement. J Biol Chem 273(43):31718-31725

Legrand D, Vigié K, Said EA, Elass E, Masson M, Slomianny MC, Carpentier M, Briand JP, Mazurier J, Hovanessian AG (2004) Surface nucleolin participates in both the binding and endocytosis of lactoferrin in target cells. Eur J Biochem 271(2):303-317

Losfeld ME, El Khoury D, Mariot P, Carpentier M, Krust B, Briand JP, Mazurier J, Hovanessian AG, Legrand D (2009) The cell surface expressed nucleolin is a glycoprotein that triggers calcium entry into mammalian cells. Exp Cell Res 315(2):357-369

Lynch EM, Moreland RB, Ginis I, Perrine SP, Faller DV (2001) Hypoxia-activated ligand HAL-1/13 is lupus autoantigen Ku80 and mediates lymphoid cell adhesion in vitro. Am J Physiol Cell Physiol 280(4):C897-C911

Nisole S, Krust B, Callebaut C, Guichard G, Muller S, Briand JP, Hovanessian AG (1999) The anti-HIV pseudopeptide HB-19 forms a complex with the cell-surface-expressed nucleolin independent of heparan sulfate proteoglycans. J Biol Chem 274(39):27875-27884

Nisole S, Said EA, Mische C, Prevost MC, Krust B, Bouvet P, Bianco A, Briand JP, Hovanessian AG (2002) The anti-HIV pentameric pseudopeptide HB-19 binds the C-terminal end of nucleolin and prevents anchorage of virus particles in the plasma membrane of target cells. J Biol Chem 277(23):20877-20886

Ohshima Y, Yajima I, Takeda K, Iida M, Kumasaka M, Matsumoto Y, Kato M (2010) c-RET molecule in malignant melanoma from oncogenic RET-carrying transgenic mice and human cell lines. PLoS One 5(4):e10279

Orrick LR, Olson MO, Busch H (1973) Comparison of nucleolar proteins of normal rat liver and Novikoff hepatoma ascites cells by two-dimensional polyacrylamide gel electrophoresis. Proc Natl Acad Sci U S A 70(5):1316-1320

Ozawa D, Nakamura T, Koike M, Hirano K, Miki Y, Beppu M (2013) Shuttling protein nucleolin is a microglia receptor for amyloid beta peptide 1-42. Biol Pharm Bull 36(10):1587-1593

Pfeifle J, Anderer FA (1983) Isolation and characterization of phosphoprotein pp 105 from simian virus 40-transformed mouse fibroblasts. Biochim Biophys Acta 762(1):86-93

Pfeifle J, Hagmann W, Anderer FA (1981) Cell adhesion-dependent differences in endogenous protein phosphorylation on the surface of various cell lines. Biochim Biophys Acta 670(2):274-284

Reyes-Reyes EM, Akiyama SK (2008) Cell-surface nucleolin is a signal transducing P-selectin binding protein for human colon carcinoma cells. Exp Cell Res 314(11-12):2212-2223

Rubinstein DB, Stortchevoi A, Boosalis M, Ashfaq R, Ghebrehiwet B, Peerschke EI, Calvo F, Guillaume T (2004) Receptor for the globular heads of $\mathrm{C} 1 \mathrm{q}$ (gC1q-R, $\mathrm{p} 33$, hyaluronan-binding protein) is preferentially expressed by adenocarcinoma cells. Int $\mathbf{J}$ Cancer 110(5):741-750

Semenkovich CF, Ostlund RE Jr, Olson MO, Yang JW (1990) A protein partially expressed on the surface of HepG2 cells that binds lipoproteins specifically is nucleolin. Biochemistry (Mosc) 29(41):9708-9713

Shi H, Huang Y, Zhou H, Song X, Yuan S, Fu Y, Luo Y (2007) Nucleolin is a receptor that mediates antiangiogenic and antitumor activity of endostatin. Blood 110(8):2899-2906

Sinclair JF, O'Brien AD (2002) Cell surface-localized nucleolin is a eukaryotic receptor for the adhesin intimin-gamma of enterohemorrhagic Escherichia coli O157:H7. J Biol Chem 277(4):2876-2885

Soundararajan S, Wang L, Sridharan V, Chen W, Courtenay-Luck N, Jones D, Spicer EK, Fernandes DJ (2009) Plasma membrane nucleolin is a receptor for the anticancer aptamer AS1411 in MV4-11 leukemia cells. Mol Pharmacol 76(5):984-991

Srivastava M, Pollard HB (1999) Molecular dissection of nucleolin's role in growth and cell proliferation: new insights. FASEB J 13(14):1911-1922

Srivastava M, Fleming PJ, Pollard HB, Burns AL (1989) Cloning and sequencing of the human nucleolin cDNA. FEBS Lett 250(1):99-105

Srivastava M, McBride OW, Fleming PJ, Pollard HB, Burns AL (1990) Genomic organization and chromosomal localization of the human nucleolin gene. J Biol Chem 265(25):14922-14931

Storck S, Thiry M, Bouvet P (2009) Conditional knockout of nucleolin in DT40 cells reveals the functional redundancy of its RNAbinding domains. Biol Cell 101(3):153-167

Suganuma M, Okabe S, Marino MW, Sakai A, Sueoka E, Fujiki H (1999) Essential role of tumor necrosis factor $\alpha$ (TNF- $\alpha$ ) in tumor promotion as revealed by TNF- $\alpha$-deficient mice. Cancer Res 59(18):4516-4518

Suganuma M, Kurusu M, Okabe S, Sueoka N, Yoshida M, Wakatsuki Y, Fujiki H (2001) Helicobacter pylori membrane protein 
1: a new carcinogenic factor of Helicobacter pylori. Cancer Res 61(17):6356-6359

Suganuma M, Okabe S, Kurusu M, Iida N, Ohshima S, Saeki Y, Kishimoto T, Fujiki H (2002) Discrete roles of cytokines, TNF$\alpha$ IL-1, IL-6 in tumor promotion and cell transformation. Int $\mathbf{J}$ Oncol 20(1):131-136

Suganuma M, Kurusu M, Suzuki K, Nishizono A, Murakami K, Fujioka T, Fujiki H (2005) New tumor necrosis factor- $\alpha$-inducing protein released from Helicobacter pylori for gastric cancer progression. J Cancer Res Clin Oncol 131(5):305-313

Suganuma M, Yamaguchi K, Ono Y, Matsumoto H, Hayashi T, Ogawa T, Imai K, Kuzuhara T, Nishizono A, Fujiki H (2008) TNF- $\alpha-$ inducing protein, a carcinogenic factor secreted from $H$. pylori, enters gastric cancer cells. Int J Cancer 123(1):117-122

Suganuma M, Watanabe T, Yamaguchi K, Takahashi A, Fujiki H (2012) Human gastric cancer development with TNF- $\alpha$ inducing protein secreted from Helicobacter pylori. Cancer Lett 322(2): 133-138

Tate A, Isotani S, Bradley MJ, Sikes RA, Davis R, Chung LW, Edlund M (2006) Met-independent hepatocyte growth factor-mediated regulation of cell adhesion in human prostate cancer cells. BMC Cancer 6:197

Tayyari F, Marchant D, Moraes TJ, Duan W, Mastrangelo P, Hegele RG (2011) Identification of nucleolin as a cellular receptor for human respiratory syncytial virus. Nat Med 17(9):1132-1135

Tsuge H, Tsurumura T, Utsunomiya H, Kise D, Kuzuhara T, Watanabe T, Fujiki H, Suganuma M (2009) Structural basis for the Helicobacter pylori-carcinogenic TNF- $\alpha$-inducing protein. Biochem Biophys Res Commun 388(2):193-198
Ugrinova I, Monier K, Ivaldi C, Thiry M, Storck S, Mongelard F, Bouvet P (2007) Inactivation of nucleolin leads to nucleolar disruption, cell cycle arrest and defects in centrosome duplication. BMC Mol Biol 8:66

Virchow R (1858) Reizung und Reizbarkeit. Arch pathol Anat u Physiol u klin Medizin 14:1-63

Watanabe T, Hirano K, Takahashi A, Yamaguchi K, Beppu M, Fujiki $\mathrm{H}$, Suganuma M (2010a) Nucleolin on the cell surface as a new molecular target for gastric cancer treatment. Biol Pharm Bull 33(5):796-803

Watanabe T, Tsuge H, Imagawa T, Kise D, Hirano K, Beppu M, Takahashi A, Yamaguchi K, Fujiki H, Suganuma M (2010b) Nucleolin as cell surface receptor for tumor necrosis factor- $\alpha$ inducing protein: a carcinogenic factor of Helicobacter pylori. J Cancer Res Clin Oncol 136(6):911-921

Watanabe T, Takahashi A, Suzuki K, Kurusu-Kanno M, Yamaguchi K, Fujiki H, Suganuma M (2013) Epithelial-mesenchymal transition in human gastric cancer cell lines induced by $\mathrm{TNF}-\alpha$-inducing protein of Helicobacter pylori. Int $\mathrm{J}$ Cancer. doi:10.1002/ijc. 28582

Yamagiwa K, Ichikawa K (1915) Experimentelle Studie über die Pathogenese der Epithelialgeschwülste. Mitteilungen Med Fakultät Kaiserl Univ Tokyo 15:295-344

Yoshida M, Wakatsuki Y, Kobayashi Y, Itoh T, Murakami K, Mizoguchi A, Usui T, Chiba T, Kita T (1999) Cloning and characterization of a novel membrane-associated antigenic protein of Helicobacter pylori. Infect Immun 67(1):286-293 